“C 2017 IEEE. Personal use of this material is permitted. Permission from IEEE must be obtained for all other uses, in any current or future media, including reprinting/republishing this material for advertising or promotional purposes, creating new collective works, for resale or redistribution to servers or lists, or reuse of any copyrighted component of this work in other works." 


\section{IEEE AP Distinguished Achievement Awardee, Prof. Georges A. Deschamps, A True Gentleman and Distinguished Scholar}

\author{
University of Technology Sydney \\ Global Big Data Technologies Centre \\ Ultimo NSW 2007, Australia \\ Richard.Ziolkowski@uts.edu.au
}

\author{
Richard W. Ziolkowski \\ The University of Arizona \\ Department of Electrical and Computer Engineering \\ Tucson, AZ 85721, USA \\ ziolkowski@ece.arizona.edu
}

\begin{abstract}
Prof. Georges Armand Deschamps was a distinguished scholar, inventor, advisor, and mentor. As a Senior Engineer with the Federal Telecommunications Laboratory and then the Head of the Antenna Laboratory at the University of Illinois at Urbana-Champaign, he championed many pioneering efforts including microstrip antennas, frequency independent antennas, ray techniques, and the use of advanced mathematical methods in electromagnetics, such as quaternions, hyperbolic geometries, and differential forms, to solve many practical and important engineering problems.
\end{abstract}

Keywords-Differential forms, Distinguished Achievement Award, fast Fourier transform, frequency independent antennas, high frequency asymptotics, hyperbolic protractor, patch antenna

\section{EARLY YEARS}

Prof. Georges A. Deschamps (see Fig. 1) was born in Vendome, France in 1911. Growing up in Normandy, he had a keen interest in sailing. He received his scientific education at the École Normale Supérieure in Paris, one of the famous French "Grandes Ecoles". Being admitted in 1931, one of his classmates was the late French Prime Minister, Georges Pompidou. While graduating in mathematics, his interests extended into theoretical physics. He also received advanced degrees in mathematics and physics from the Sorbonne in Paris. After graduation, Prof. Deschamps was planning to study topology with E. Cech in Brno, Czechoslovakia, but an unexpected offer changed his mind and in 1937 he spent a year of research at Princeton University. He then spent some time teaching mathematics and physics at the Lycee Francais de New York. However, when World War II erupted, he was called to duty. Lieutenant Deschamps helped calculate projectile trajectories on the Maginot Line. When it fell to the German campaign at Ardennes in 1940, he made a harrowing escape through north Africa and returned to the USA in 1941, where he resumed his teaching career in New York. During a series of lectures by L. Brillouin, Prof. Deschamps recognized the relationship between quadrupole analysis, Lorentz group representations, and models of non-Euclidean geometry, which later germinated into practical engineering applications.

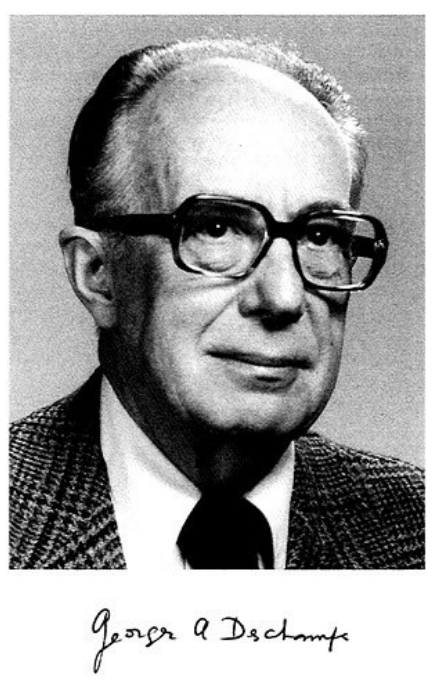

Fig. 1. Professor Georges A. Deschamps, a true gentleman and distinguished scholar

\section{ITT YEARS}

Prof. Deschamps became a Project Engineer for the Federal Telecommunications Laboratories, a division of ITT Corp. (International Telephone and Telegraph) in 1947. He was assigned to work on direction finding and radio navigation. With his background, he invented an inertial navigation system based on quaternion algebra and used non-Euclidean (hyperbolic) geometry to solve transmission line, waveguide junction, and polarization problems. His "hyperbolic protractor" allowed the graphical solution to a large variety of Smith chart problems [1]. He also contributed to the theory of wave propagation in magnetized plasmas and the graphical representation of dispersion surfaces. Essentially the same work was published two years later by Clemmov et al and it is known as the CMA diagram. He also computed Fourier transforms with the Cooley-Tukel algorithm, 10 years before those latter researchers published it in 1965. Furthermore, at the Third Symposium on the USAF Antenna Research and Development Program held at Robert Allerton Park in 1953, he presented the work entitled "Microstrip microwave antennas", revealing the first concept of a "patch antenna" [2]. 


\section{UIUC YEARS.}

In 1958, Prof. Deschamps joined the University of Illinois at Urbana-Champaign as Director of the Antenna Laboratory. He was recruited to the position by the Department Chairman, Dr. Edward C. Jordan, to replace Dr. Victor Rumsey who left in 1957 and to lead the team that was developing frequency independent antennas [3]. One lab outcome was Prof. John Dyson's invention of the log-periodic spiral antenna.

Until his retirement in 1982, Prof. Deschamps made several highly original and significant contributions to several areas, always highlighting his geometrical intuition and exceptional mathematics background. He was a leader in the theories of high frequency asymptotics [4], including the uniform theory of diffraction [5]. He introduced the concepts of complex source representations of Gaussian beams [6] and led the development of complex ray tracing for scattering problems [7]. He was a strong proponent for using differential forms to describe in a coordinate-free manner a variety of electromagnetic phenomena [8]. He introduced Feynman diagram-like representations of electromagnetic scattering [9]. While not being a prolific writer, when he did write something, it was a recognized gem. His IEEE Proceedings papers in 1972 on "Ray techniques in electromagnetics" [4] and in 1981 on "Electromagnetics and differential forms" [8] are very wellknown, unique contributions to electromagnetic theory. He was an IEEE Life Fellow. He was elected to the National Academy of Engineering in 1978. He received the IEEE Centennial Medal in 1984. He was selected for the 1IEEE AP-S Distinguished Achievement Award in 1987.

I was Prof. Deschamps' last Ph.D. student, being with him during his final years at UIUC (he retired in 1982) and working with him on high frequency asymptotics problems. I was an unhappy physics $\mathrm{PhD}$ student getting ready to leave UIUC for business school. The EE Chairman thought I would waste my life going to Stanford B-school simply to make tons of money. He introduced me to Prof. D and we hit it off immediately. After a brief, but intense struggle with the Chairman of the physics department who thought electromagnetics (EM) was a dead physics area, I was allowed to pursue my physics degree through Prof. D. The antenna lab was a very vibrant group at the time; it included several EM luminaries: Profs. Andy (Shung-Wu) Lee, Y. T. Lo, and Raj Mittra. As one would imagine, Prof. D mentored me through his strengths as I researched engineering applications based on theoretical physics and differential geometry. My dissertation was on high frequency asymptotics in phase space on Lagrangian manifolds to overcome the known problems of ray tracing through caustic regions [10]. Our work included a SIAM paper on the "Asymptotic Poincare Lemma" [11] and comparisons of Clifford algebra and differential form representations of EM fields which I had the honor to present to a primarily mathematics oriented NATO workshop in Canterbury, England [12]. I was connected to my first position, which was with the Lawrence Livermore National Laboratory, through a former UIUC antenna lab student, Dr. Hrair Cabayan, who had worked with Prof. D and who understood my background and appreciated my talents.
Prof. Deschamps was more than an exceptional researcher. He was a very generous, but very fair person. While being recognized as a pillar of strength academically, he was modest and led a quiet life. He was respected as a person who generously shared his knowledge and time with students and his colleagues. During my years with Prof. D, he would spend his summers on Long Island with his lovely wife, Bunty (Elsa), sailing and enjoying their three children (François, Georgianne, and Christiane) and their families, and sometimes in Paris reconnecting with hallmarks from their Sorbonne days. He enjoyed describing how he would use one of his fondest inventions, his hyperbolic protractor, to navigate with the stars while sailing at night in Long Island sound. Prof. Deschamps passed away in 1998 at the age of 86 after a long illness.

I was truly rewarded both personally and professionally for having worked with one the greats in EM history, Prof. Georges A. Deschamps.

\section{ACKNOWLEDGMENTS}

The author would like to express his sincere thanks to Prof. Yahya Rahmat-Samii, UCLA, for his contributions to this effort. As a graduate and post-doctoral student with the UIUC antenna laboratory, he too had many impactful interactions with "Big G". Our chance meeting his last and my first week at the lab grew into a longstanding professional friendship.

\section{REFERENCES}

[1] G. A. Deschamps, "A hyperbolic protractor for microwave impedance measurements and other purposes," Federal Telecommunications Laboratories, Nutley, NJ, 1953.

[2] G. A. Deschamps, "Microstrip microwave antennas," in Proc. 3rd USAF Symposium on Antennas, pp. 22-26, 1953.

[3] E. C. Jordan; G. A. Deschamps; J. D. Dyson; P. E. Mayes, "Developments in broadband antennas," IEEE Spectrum, vol. 1, no. 4, pp. 58-71, Apr. 1964.

[4] G. A. Deschamps, "Ray techniques in electromagnetics," Proc. IEEE, vol. 60, no. 9, pp. 1022-1035, Sep. 1972.

[5] S. W. Lee and G. A. Deschamps, "A uniform asymptotic theory of electromagnetic diffraction by a curved wedge," IEEE Trans. Antennas Propag., vol. 24, no. 1, pp. 25-34, Jan. 1976.

[6] W.-Y. D. Wang and G. A. Deschamps, "Application of complex ray tracing to scattering problems," Proc. IEEE, vol. 62, no. 11, pp. 1541 1551, Nov. 1974

[7] G. A. Deschamps, "Gaussian beam as a bundle of complex rays," Electron. Lett., vol. 7, no. 23, pp. 684-685, Nov. 1971.

[8] G. A. Deschamps, "Electromagnetics and differential forms," Proc. IEEE, vol. 69, no. 6, pp. 676-696, Jun. 1981.

[9] G. A. Descamps, "Scattering diagrams in electromagnetic theory," in Electromagnetic Theory and Antennas, E. C. Jordan, ed., Pergamon Press, New York, 1963, pp. 235-251.

[10] R. W. Ziolkowski and G. A. Deschamps, "Asymptotic evaluation of high-frequency fields near a caustic: An introduction to Maslov's method," Radio Sci., vol. 19(4), pp. 1001-1025, 1984.

[11] R. W. Ziolkowski and G. A. Deschamps, "The asymptotic Poincaré lemma and its applications," SIAM J. Math. Anal., vol. 15(3), pp. 535$558,1984$.

[12] Georges A. Deschamps and R. W. Ziolkowski, "Comparison of Clifford and Grassmann algebras in applications to electromagnetics," Clifford Algebras and Their Applications in Mathematical Physics, J. S. R. Chisholm and A. K. Commons (eds.), D. Reidel, pp. 501-515, London, 1986 